\title{
Dyke-Davidoff Masson Syndrome
}

\author{
S SHARMA, D GOYAL, A NEGI, RG SOOD, A JHOBTA, M SURYA
}

Ind J Radiol Imag 2006 16:2:165-166

\section{Keywords: Hemiatrophy, Dyke-Davidoff Masson Syndrome}

$\mathrm{D}$ yke-Davidoff-Masson Syndrome (DDMS) refers to atrophy or hypoplasia of one cerebral hemisphere (hemiatrophy) which is secondary to brain insult in fetal or early childhood period. Hemiatrophy is not frequently encountered in clinical practice. We present here a case of a 35 year old woman who presented with seizures and weakness of left upper-limb and on CT was diagnosed to have DDMS.

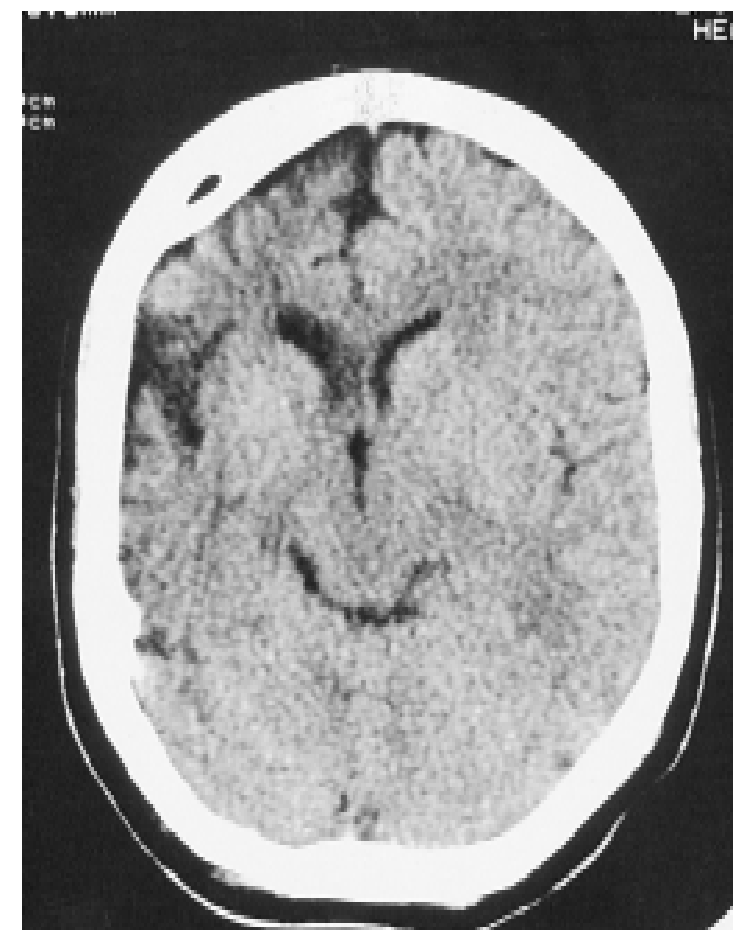

Fig 1: Plain CT Head showing atrophy of the right cerebral hemisphere with dilated ipsilateral lateral ventricle and widened Sylvian fissure. There is also thickening of the calvarium on right side.

\section{CASE REPORT:}

A woman aged 35 years presented to the medical OPD with complaints of seizures for past 15 years and weakness in left upper limb since birth. Her seizures were controlled with Carbamezepine but now for last one month she had seizures even when on regular medication. On examination, there was a slight increase in the left biceps and triceps reflexes. A plain and contrast CT head was done which revealed atrophy of the right cerebral hemisphere with dilatation of the ipsilateral lateral ventricle, widening of right sided Sylvian fissure (Fig. 1) and ipsilateral sulci (Fig. 2). Also there was widening of the diploic space on right side with enlarged right frontal sinus and mastoid-air cells (Fig 3). So a diagnosis of DDMS was made.

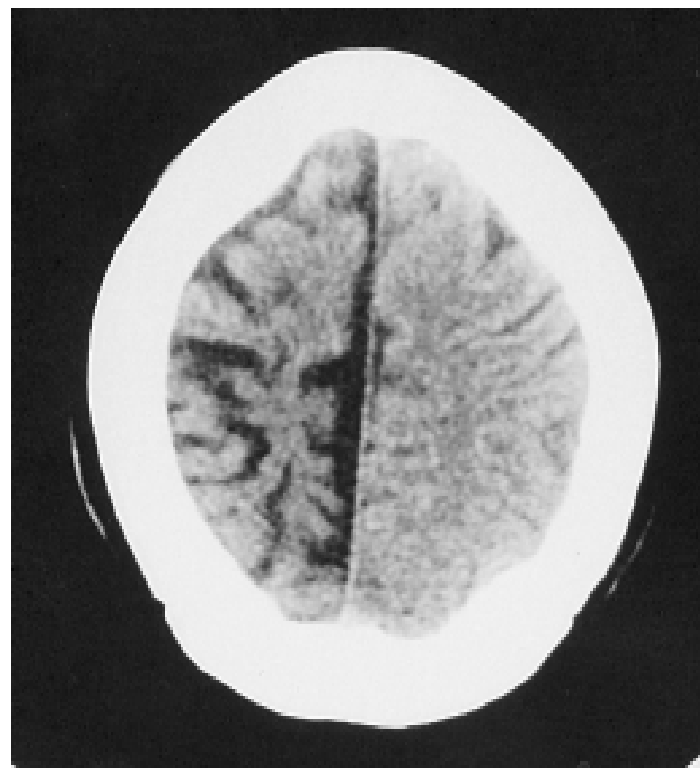

Fig 2: Plain CT Head showing widening of the sulci and atrophy of gyri of right cerebral hemisphere.

\section{DISCUSSION:}

In 1933, Dyke, Davidoff, and Masson described the plain skull radiographic and pneumatoencephalographic changes in a series of nine patients characterized clinically by hemiparesis, seizures, facial-asymmetry, and mental retardation [1]. The plain skull radiographic changes included thickening of calvarium and dilatation of ipsilateral frontal and ethmoid sinuses. Also, there was

From the Radiodiagnosis Deptt. IG Medical College, Shimla. 171001 (H.P.)

Request for Reprints: Dr Sanjeev Sharma, 1007, Basant Vihar, Kasumpti, Shimla. (H.P.) - 171009

Received 20 August 2005; Accepted 10 March 2006 
elevation of the greater wing of sphenoid and petrous ridge and upward tilting of planum- sphenoidale.

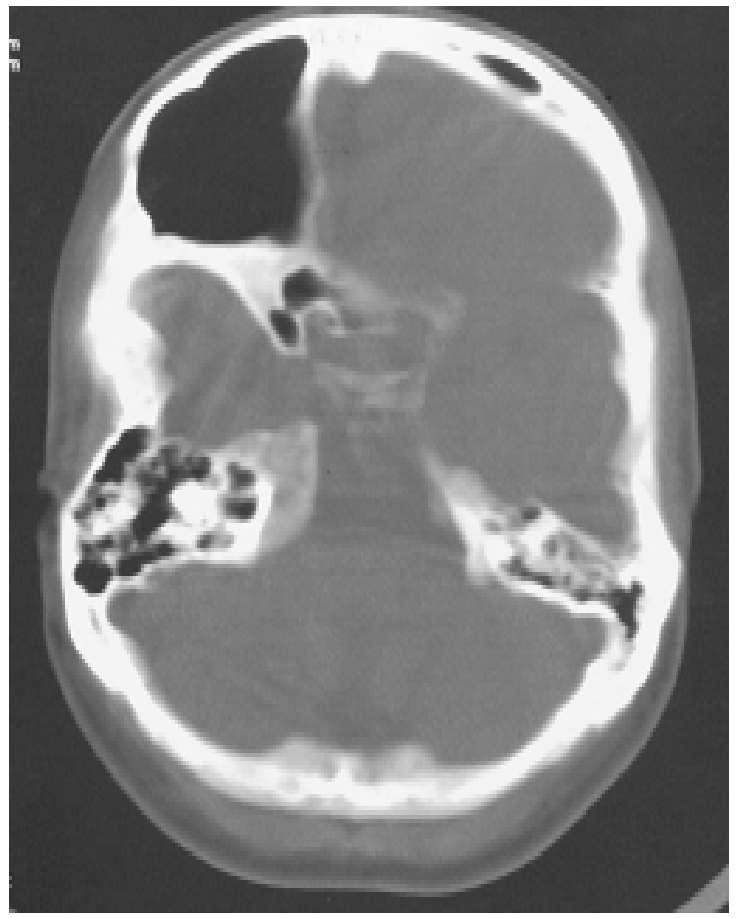

Fig 3: CT Head (bone window) showing enlarged right frontal sinus and mastoid air cells.

In 1939, Alpers and Dear defined two types of cerebral hemiatrophy [2]. In the primary (congenital) type, the entire cerebral hemisphere is characteristically hypoplastic. The secondary type results from a cerebrovascular lesion, inflammatory process, or cranial trauma. Twenty-two cases of primary variety were collected from the literature until 1939. A clinical triad of hemiplegia, seizures and mental retardation was defined. However mental retardation was not always present and seizures may appear months or years after the onset of hemiparesis [3].

According to Hageman et al, since primary cerebral atrophy is actually a lack of cerebral development rather than atrophy the terms cerebral hemi-hypoplasia or unilateral cerebral hypoplasia would be more appropriate [4]. The brain reaches half of its adult size during the first year of life and reaches three-fourths of that size by the end of third year. As it enlarges, the brain presses outward on the bony tables and is partly responsible for the gradual enlargement and general shape of the adult head. When the brain fails to grow properly, the other structures tend to direct their growth inward, thus accounting for the enlargement of the frontal sinus, the increased width of the diploic space and the elevations of the greater wing of sphenoid and the petrous ridge on the affected side [5]. These changes can occur only when brain damage is sustained before three years of age however, such changes may become evident as soon as nine-months after brain damage was sustained [6].

A vascular cause of cerebral hemiatrophy (hypoplasia), first proposed in 1860 was confirmed in later studies [7]. It was proposed that a vascular anomaly occurring in very early gestation (five or six weeks) may result in a major defect in brain development whereas those occurring later may produce more localized lesions [8]. It was reported that decrease in carotid artery flow due to coarctation of aorta can also cause cerebral hemiatrophy. Crossed cerebellar atrophy is usually associated with long standing, extensive and unilateral cerebral lesions with onset during infancy or early childhood. The manifestations of DDMS may be so subtle as to be overlooked on plain radiographs; however, $\mathrm{CT}$ is the diagnostic modality of choice.

Other differential diagnosis to be considered in a patient of cerebral hemiatrophy are Sturge-Weber Syndrome, some brain tumours, Silver Syndrome, as well as conditions, that are associated with unilateral magelancephaly as in the linear-nevus syndrome. A proper clinical history and CT findings provide the correct diagnosis.

\section{REFERENCES:}

1. Dyke C G, Davidoff L M and Masson C B, Cerebral Hemiatrophy and homolateral hypertrophy of the skull and sinuses. Surg Gynecol Obstet 1933; 57: 588-600.

2. Alpers $B \mathrm{~J}$ and Dear R B, Hemiatrophy of the brain. $\mathrm{J}$ Nerv Ment Dis 1939; 89: 653-651.

3. Zilkha A, CT of cerebral hemiatrophy, AJR 1980; 135 259-262.

4. Hageman G, Gooskens R H J M, Willemse J, A cerebral cause of arthrogryposis: Unilateral cerebral hypoplasia. Clin Neurol Neurosurg 1985; 87: 119-119-122.

5. Parker C E, Harris N and Mavalwala J, Dyke-DavidoffMasson Syndrome: Five case studies and deductions from dermatoglyphics. Clinical Pediatrics 1972; 11(5): 288-292.

6. Solomon G E, Hilal S K, Gold A P, et al, Natural history of acute hemiplegia of childhood. Brain 1970; 93: 107-120.

7. Teal J S, Rumbaugh C L, Bergeron R T, et al, Congenital absence of internal carotid artery associated with cerebral hemiatrophy, absence of the external carotid artery. AJR 1973; 18: 534-545.

8. Parker J C, Gaede J T, Occurrence of vascular anomalies in unilateral cerebral hypoplasia "cerebral hemiatrophy". Arch Pathol Lab Med 1970; 90: 265-270. 